\title{
Synthesis and Characterization of Core-shell Microspheres with Double Thermosensitivity
}

\author{
Yilong Chen, Julien E. Gautrot, X. X. Zhu* \\ Département de chimie, Université de Montréal, \\ C.P. 6128, succursale Centre-ville, Montréal, Québec, Canada, H3C 3J7
}

Supporting Information

*To whom correspondence should be addressed.

Tel: 514-340-5172; Fax: 514-340-5290; E-mail: julian.zhu@ umontreal.ca. 

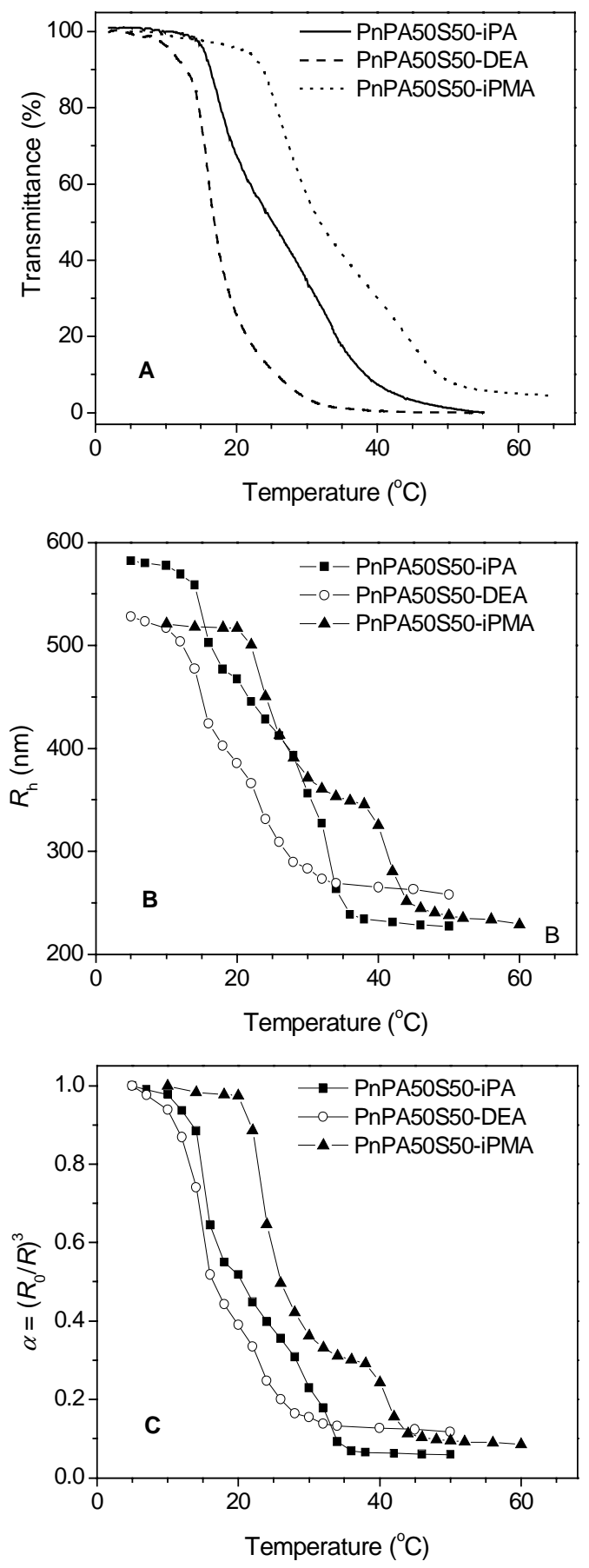

Figure S1. Optical transmittance (A), hydrodynamic diameter $R_{\mathrm{h}}(\mathrm{B})$ and swelling ratio $\left(\mathrm{C}, \alpha=\left(R_{0} / R_{\mathrm{h}}\right)^{3}\right)$ of doubly thermosensitive core-shell miscrospheres (PnPA50PS50 derivatives) as a function of temperature. 